\title{
LA DIFUSIÓN DE LUIS DE MORALES EN BOHEMIA
}

\author{
POR \\ PAVEL ŠTĚPÁNEK \\ Palachéko Universita, Olomouc
}

\begin{abstract}
La reciente subasta de una Piedad atribuida al taller de Morales en Praga, da motivo para repasar la presencia de la obra de este artista español en Praga y el Reino de Bohemia que data ya del s. xvi, pues un cuadro con este tema, que estaba en la Catedral, parece que fue destruido durante la devastación calvinista. A través de una posible copia de menor calidad y en papel, guardada en el monasterio de los servitas de Praga, subsiste el testimonio del interés que suscitaba Morales en la ciudad checa de Prestice.
\end{abstract}

Palabras clave: Luis de Morales. Piedad. Praga. Bohemia. Copias.

The recent auction in Prague of a Pietá attributed to the workshop of Morales, offers the occasion to review the presence of works by this Spanish artist in Prague and the Kingdom of Bohemia. It would seem that they had already arrived by the 16th century, given that a painting of this theme in the Cathedral apparently was destroyed during the Protestant Reformation. Through a possible copy on paper of inferior quality in the Servite Monastery of Prague, a testimony remains of the interest in Morales in the Czech city of Prestice.

Key words: Luis de Morales. Pietá. Prague. Bohemia. Copies.

En una de sus últimas actividades, la recién desaparecida Galería Brandl ${ }^{1}$ de Praga, expuso un cuadro atribuido a Luis de Morales (1515-1586).

Éste apareció luego, como propiedad de un coleccionista privado, en la exposición de $\mathrm{Fe}$ lipe II y su época, celebrado en Praga ${ }^{2}$. Así, se nos ofrece dar a conocer ahora una obra de Morales, así como, a la vez, una oportunidad para una consideración acerca de la difusión de la obra de Morales y su arraigo en el Reino de Bohemia.

Se trata de una Piedad, más exactamente la Virgen abrazando al Cristo muerto (óleo sobre tabla de álamo, ó chopo, 38,6 × 28,5 cm). Unidas las dos figuras en un bloque vertical, alargado, logra una expresión más patética, con una tensión en altura, acentuada por el ma-

${ }^{1}$ El cuadro se reproduce a color en el folleto de información acerca de la galería Galerie Petra Brandla, Regulus, Praga 1994, s. p. Esta galería era una de las primeras que surgieron como resultado de la iniciativa privada después del cambio político en 1989.

${ }^{2}$ Felipe II (1527-1598) y su época. Piezas selectas de arte y documentos en colecciones de Praga. Embajada de España en Praga y Museo Nacional de Praga. Palacio Lobkowicz, El Castillo de Praga, del 19 de enero al 28 de febrero (Catálogo e introducción de Pavel Śtǵpánek). La Embajada de España hizo posible, con su aporte económico, llevar a cabo el evento, seguido de un simposio internacional sobre el tema. 
dero que emerge del fondo y que respalda al grupo, como puede observarse en toda una serie de obras de este tema en la obra del pintor ${ }^{3}$. El nimbo de la Virgen está apenas sugerido. Los colores principales son el azul del manto y el blanco del velo, aparte del encarnado, cadavérico en caso de Cristo, con acentos de las gotas rojas de la sangre sobre todo en su frente y en los ojos. Los pliegues son bastante esquemáticos, el fondo verduzco a la derecha; toda la pintura parece ser un poco seca. Recordemos la opinión de que la inspiración directa de Morales hay que buscarla en las tallas que son las que mejor interpretan la sensibilidad de este momento ${ }^{4}$.

En cuanto a la composición, la obra más próxima parece ser la Piedad, atribuida a Morales en el Museo Diocesano de Sigüenza. Se destaca en ella «el gesto majestuosamente doloroso de la virgen, sus ojos conmovedores, el rictus angustiado de su boca» ${ }^{5}$. Sin embargo, incluso en una reproducción se nota perfectamente que se trata de una pintura más seca, más esquemática, así que, si hay que tomar una opinión, es, claramente, a favor de la versión de Praga. Parece que en esto coinciden todas las consultas hechas en España, que ciertamente se trata de una pieza auténtica, salida del taller de Morales ${ }^{6}$.

Antes de considerar otras versiones y réplicas del tema, parece oportuno y conveniente hacer un brevísimo resumen de lo que se opina últimamente acerca de la obra de Morales. Esta ha sido siempre tomada en consideración, aunque quedó sin una monografía adecuada hasta hace poco tiempo. Cuando Juan Antonio Gaya Nuño escribió, hace cuatro decenios, su pequeña monografía sobre uno de los artistas españoles del siglo Xvi más conocidos en Europa, presentó su trabajo como una «suma de planteamientos previos» ${ }^{7}$, que resumió lo publicado por Elisabeth du Gué Trapier ${ }^{8}$, agregando observaciones nuevas. Un año después aparece fuera de España la monografía de Baeckbacka ${ }^{9}$, hasta ahora, parece, no superada en muchos aspectos. Luego, Carmelo Solís aportó nuevos documentos ${ }^{10}$ para pasar, un cuarto de siglo después, en 1999, a realizar una monografía sin $\operatorname{par}^{11}$. Morales es, en la definición más breve posible, «un artista complejo y personal, que funde modelos italianos, técnica precisionista flamenca y un cierto y apasionado expresionismo piadoso de fondo manierista» ${ }^{12}$. Su estilo continuó siendo imitado en su próspero taller y por discípulos entre los que figuran sus hijos. Hizo especialmente populares los temas de la Virgen con el Niño, los Ecce Homo, Cristo en la columna, y, sobre todo, la Piedad ${ }^{13}$. La imitación se debe, entre otras cosas, a que la imagen religiosa cumplía unas funciones efectivas y didácticas hasta que se observa un proceso de «inflación» que alcanzó «un claro fenómeno de reiteración» ${ }^{14}$. Es precisamente el caso de las Piedades que

\footnotetext{
${ }^{3}$ Camón Aznar, José, La pintura española del siglo Xvi. Summa Artis, Madrid 1979, p. 474.

${ }^{4}$ Camón, J., op. cit., p. 461.

${ }^{5}$ Gil Peces y Rata, Felipe, Museo Diocesano de Arte, 6a. edición revisada y aumentada, Sigüenza, 1988, p. 15-16, y La catedral y el Museo Diocesano de Sigüenza. Zaragoza 1992, p. 99, fig. 121. Agradezco a Peter Kováč la cesión de algunas fotografías que me han permitido orientarme mejor en el tema iconográfico. La pintura de Morales en Sigüenza, en un rico marco dieciochesco, no publicada fuera del ámbito de la ciudad. No se dan a conocer las medidas ni los detalles técnicos del soporte.

${ }^{6}$ Antonio, Trinidad de, en una carta del 25 de mayo de 1994 a Peter Kováč; también A. E. Pérez Sánchez tuvo la misma opinión en una consulta que le hice hará tiempo.

${ }^{7}$ Gaya Nuño, Juan Antonio, Luis de Morales, Madrid 1961, p. 7.

${ }^{8}$ Gué Trapier, E. du, Luis de Morales and Leonardesque influences in Spain. New York 1953.

${ }^{9}$ Baeckbacka, Ingjald, Luis de Morales, Helsinki 1962.

${ }^{10}$ Los Morales de la Catedral de Badajoz, Badajoz, junio 1975. Además, hay sendos estudios de Manuel Álvarez Fijo y Manuel Terrón Albarán. Véase también Solís Rodríguez, Carmelo, Un inédito Morales en Montijo, Badajoz, $1972, \mathrm{p} 11$.

${ }^{11}$ Solís Rodríguez, Carmelo, Luis de Morales, Badajoz 1999. Debo a Carmelo Solís la posibilidad de ver los Morales en Badajoz, hace 25 años, y, luego, cuando tuve la suerte de verle otra vez poco antes de morir. Su espléndida monografía será un punto de partida indispensable para todo investigador de Morales.

12 Pérez Sanchez, A. E., Introducción al catálogo Panorama de la pintura española desde los Reyes Católicos a Goya, Buenos Aires, junio-agosto 1980, p. XI., p. 20.

${ }^{13}$ Pérez Sánchez, A. E., Panorama, ibidem.
}

$A E A$, LXXVIII, 2005, 310, pp. 123 a 131 
servían, según Nieto y Checa, «como medios orientados a provocar el examen de conciencia y el arrepentimiento». En ellas siempre hay «una contención formal que establece un equilibrio entre lo patético y el recogimiento». La importancia de la expresión religiosa quedó estudiada y definida por A. Rodríguez Ceballos ${ }^{15}$. Últimamente, Fernando Marías ha unido acertadamente la obra de Morales con una clientela «novadora» de pintura letrada y con un nuevo método imaginativo de meditación devocional ${ }^{16}$.

A los nuevos análisis de la obra de Morales en un contexto más amplio ${ }^{17} \mathrm{o}$ simplemente sobre su interpretación ${ }^{18}$ quisiera agregar hoy, aparte de obvias menciones de lo más reciente $^{19}$, unas observaciones propias. Es que, hasta ahora, la ausencia de Morales fue una de las lagunas del arte español en la actual República checa, tan rica en la pintura española del siglo XVI, especialmente de los retratistas de la corte, tal como se mostró en las exposiciones preparadas hace tiempo ${ }^{20}$. La tabla de Praga puede relacionarse directamente con Morales, aunque, fuera sólo con su taller. Se sabe que Morales creó sus modelos, repitiéndolos él mismo o su taller. En la Piedad de mayor desarrollo (Academia de San Fernando), la angustia del espacio, típicamente manierista, es muy sensible ${ }^{21}$. La versión más cercana, pero invertida y con ligeras variantes en la posición de las manos y en distinto traje, parece ser, la de la colección particular de Madrid, recientemente catalogada por Matías Díaz Padrón ${ }^{22}$, según el cual, la regularidad y la pasividad, con la cual el pintor «da espalda a toda demostración de la imaginación, es compensada por la sorprendente calidad de la ejecución que podría rivalizar con los pintores flamencos». Dadas las calidades técnicas y las características, Díaz Padrón la ve como una obra de juventud ${ }^{23}$. La aspereza de la versión de Praga abogaría entonces por el período más bien tardío. Hay otras variantes, de menos calidad, como la de la iglesia sevillana

\footnotetext{
${ }^{14}$ Nieto Alcaide, Víctor - Checa Cremades, Fernando, El Renacimiento. Formación y crisis del modelo clásico, Madrid 1980 , p. 338.

${ }^{15}$ Rodríguez G. de Ceballos, Alfonso, «El mundo espiritual de Luis de Morales en el Bicentenario de su muerte», Goya (Madrid) 1987, nr. 196 (enero-febrero), pp. 194-203. Nieto Alcaide - Checa Cremades, op. cit., p. 343.

${ }^{16}$ Marías, Fernando, «Luis de Morales, "El Divino"». Cuadernos de Arte Español, núm. 68, Historia 16, Madrid, 31 págs. quien presenta a Morales a la luz de «un nuevo método imaginativo de meditación devocional», pp. 17-26.

${ }^{17}$ Serrera, Juan Miguel, «Una Virgen con el Niño, de Luis de Morales», Archivo Español de Arte, 1978, núm. 202, pp. 181-184. Este autor destaca que dicho cuadro testimonia la clara vinculación leonardesca y apoya la tesis del viaje de Morales a Italia, lo cual hace insostenible asimismo su temprana vinculación con la escuela sevillana (p. 182). Con ello completa la visión de E. du Gué Trapier, op. cit., p. 18 quien ve las influencias leonardescas a través de sus alumnos e imitadores españoles de Valencia.

${ }^{18}$ Pérez Sánchez, Alfonso E., «Un nuevo y curioso documento sobre Morales», Archivo Español de Arte, 1977, núm. 199, pp. 313-316. Pérez Sánchez organizó también una exposición de El retablo de Morales en Arroyo de la Luz. Texto y notas de Alfonso E. Pérez Sánchez, Madrid, junio 1974, en el que traza un análisis breve pero completo de su obra.

${ }^{19}$ Marías, F., op. cit. en la nota 15 , p. 22, aclarando de manera radical su clientela erasmista.

${ }^{20}$ Španèlské um̌ní 14.-16. stolètí z československých sbírek (Arte español de las colecciones checoslovacas). Středočeská galerie v Praze, Praga, diciembre 1984-marzo de 1985 (catálogo Pavel Štěpánek).

${ }^{21}$ Angulo, Diego, Pintura del Renacimiento. Ars Hispaniae, 12, Madrid 1954, p. 236. Labrada, Fernando, Catálogo de las Pinturas. Real Academia de San Fernando. Madrid 1965, p. 59, n 612. Este catálogo da a conocer otras versiones en Barcelona (col. Balansó), Parroquia de Ducy-Sainte Marguerite (Francia), y col. particular de Madrid. Véase también el catálogo de la exposición de la Academia de San Fernando. Caja de Ahorros de Salamanca, Sala en la Casa de Alba, E. S. Eloy, septiembre - octubre 1981, $\mathrm{n}^{\circ} 12,612,126 \times 98 \mathrm{~cm}$. Procede del Colegio de los Jesuitas de Córdoba.

${ }^{22}$ Díaz Padrón, Matías, 1968, p. 17 y núm. C 22. Óleo sobre tela, $57 \times 41$. Díaz Padrón se refiere a réplicas idénticas, sobre todo la del depósito del Prado núm. 2513, en la Casa de Colón, en Las Palmas, otras, en la Catedral de Málaga, en el palacio Episcopal de Madrid (Publicada en Arte Español en 1931, X, p. 185), en la colección del Vizconde del Parque Covarsi, y la de Valdés. Otras dos versiones aparecieron en dos colecciones madrileñas, de modo que hay una gran cantidad, pero éstas no corresponden exactamente a la réplica en Praga. Entre estos antecedentes podríamos mencionar también las obras de Roger van der Weiden, Descensión de Cristo donde aparece la Virgen como una Piedad besando a Cristo que aparece en Angulo Íñiguez, Diego, L'Art Flamand dans les Collections Espagnoles. Bruges, Juillet-Août 1958, p. 22, núm. 2; así como otra Piedad de Gérard David, p. 134, núm. 107 y de p. 46. núm. 17.

${ }^{23}$ Díaz Padrón, ibid. Véase otra versión en Galería Antiquaria XV, 1997, núm. 153, p. 32 y Galería Antiquaria XV 1997, núm. 147, p. 66; también ha aparecido otra en Archivo Español de Arte 1995. núm. 270, p. 225, repr.
} 
llamada de Las Teresas, en el tríptico que representa a la Magdalena, Piedad y San Juan. Asimismo se relaciona con la versión del Palacio Episcopal de Madrid.

El tipo humano de la Virgen, así como la posición de su cabeza está cerca de la Dolorosa del Museo del Ermitage de San Petersburgo ${ }^{24}$. A juzgar por la tipología, la técnica y la expresión global, al igual que por el sistema de los pliegues, a la versión de Rusia, podría decirse, sirviera como modelo alguna obra temprana. En todo caso, la versión de Praga representa a la Virgen mayor, más madura y menos dulce, más sufriente, así que es una versión variada e inédita. También podríamos mencionar en este contexto la versión del Museo Meadows, de Dallas, Texas ${ }^{25}$.

Por otra parte, son de sobra conocidos sus modelos flamencos que él reelaboró y adaptó al gusto de la época. Veo la clave del tema en el cuadro de La Piedad, cuya copia de Quentin Metsys de la segunda mitad del siglo xvi, se guarda en el Museo Municipal de Madrid (óleo sobre tela, $86 \times 50$, IN 4096) en cuyo letrero se dice: IN HOC APPARVIT CHARITAS DEI IN NOBIS QVONIAM FILIVM SVV(m) VNIGENTIVM SIT IN MVND VT VIVANS PER EV. Aun volveremos al tema iconográfico, de raíces mucho más antiguas. De creer a Ivo Kořán, su origen y prototipo habría que buscarlo en la pintura bizantina, pues también hay composiciones de este tema en la pintura gótica checa. Como Kořán no da un ejemplo concreto, quisiera completarlo. Se trata de una copia posterior, del siglo XvI, de la obra de uno de los mejores maestros del gótico checo del siglo xIV, el Maestro del Altar de Vyšší Brod, expuesta hace tiempo en México ${ }^{26}$. En esta composición observamos a Cristo enseñando su llaga mortal al mismo tiempo que su Madre se le acerca en un gesto cariñoso, besándolo. Si buscamos las raíces, tenemos que mencionar también la pintura de Ambroggio Lorenzetti, El entierro, donde la Virgen se acerca a la cabeza de Cristo muerto.

Para no ir demasiado lejos, volvamos al asunto de Morales y su inspiración flamenca. Hay dos versiones que representan un asunto muy similar, donde se acentúa el tema del beso que da la Virgen a Cristo muerto. La primera está en la Catedral de Sevilla, en la Sacristía de los Cálices, y la segunda, atribuida a la escuela de Quentin Massys, en el Museo de Amberes ${ }^{27}$. ¿Habrá conocido Morales dicha pintura en Sevilla? Dado que se destaca cada vez más su etapa sevillana, es muy probable.

Ahora bien: según varias tradiciones, la obra de Morales estuvo como mínimo en dos lugares en Praga. Una, en la propia catedral de Praga, habiendo sido destruida en el furioso ataque de los calvinistas a las obras de arte en la catedral en 1618, descrito con lujo de detalles, pero $\sin$ nombrar las obras mismas ${ }^{28}$.

\footnotetext{
${ }^{24}$ Kagane, Liudmila, Ispanskaya zhivopis XVI-XVIII vekov v Ermitazhe. Leningrado 1977, p. 16-18.

25 Véase Patton, Pamela A., «"El Prado en la Pradera": Arte español en el Museo Meadows (Dallas, Texas)». Goya $1997, \mathrm{n}^{\circ} 257$, pp. 258-274, fig. 2. Dicha tabla, muestra particularmente refinada de la obra de Morales, contiene — según la autora, en las pp. 261-262- un extenso dibujo subyacente solo visible bajo luz infrarroja. Este dibujo es una prueba de la relación de esta obra con la Piedad de la Academia de San Fernando.

${ }^{26}$ El Arte de Bohemia. Galería Nacional de Praga. Museo de San Carlos, Diciembre 1987-abril 1988, México, D. F., p. 26, $\mathrm{n}^{\circ}$ del catálogo 2, p. 74. Maestro del Altar de Vyšší Brod, copia del siglo XVI, activo a mediados del siglo XIV, Imago Pietatis, óleo sobre tabla, $79 \times 57 \mathrm{~cm}$. El artista anónimo toma su nombre del políptico de nueve tablas con escenas de la Pasión de Cristo, procedente del monasterio cisterciense de Vyšší Brod (Bohemia del Sur). Actuó como maestro principal de un gran taller y probablemente como pintor de la corte de Praga por los años 1350. Se le considera el representante más destacado de los retablos góticos checos en su primera fase de evolución. Como otra versión del tema podría considerarse la Piedad que está en la Galería Morava (Moravská galerie) de Brno, A 138, temple sobre madera, $86 \times 57$. El cuadro de la Galería Nacional de Praga fue publicado dos veces en el semanario Katolické noviny (Periódico Católico), 1983, $\mathrm{n}^{\circ} 37$, p. 3, como la Virgen Dolorosa y más tarde, 1986, $\mathrm{n}^{\circ}$ 9, p. 1, como Encuentro doloroso.

${ }^{27}$ Véase Musée d'Anvers. Recueil de 200 Photogravures d'après les chef d'oeuvres de la Galerie des Mayores Anciens. G. Hermanus, éditéur, Anvers, s. f. p. 565.

${ }^{28}$ Cuando los calvinistas estaban a punto de destruir la tumba de Fernando I, Maxmiliano I y su mujer, en la catedral de San Vito, intervino el príncipe Lobkowicz, haciéndoles salir del templo. Suele mencionarse como obra de Morales tam-
}

$A E A$, LXXVIII, 2005, 310, pp. 123 a 131 

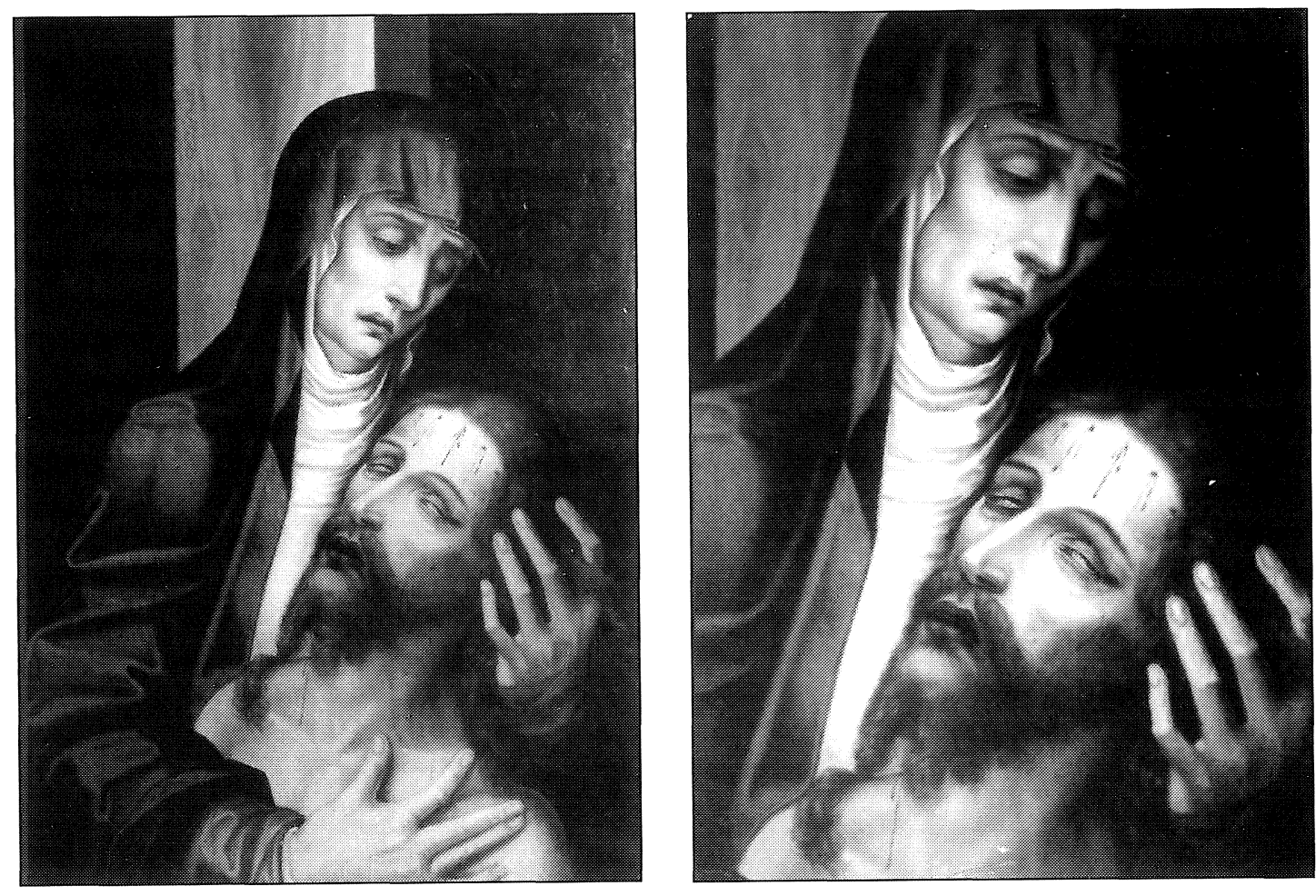

1

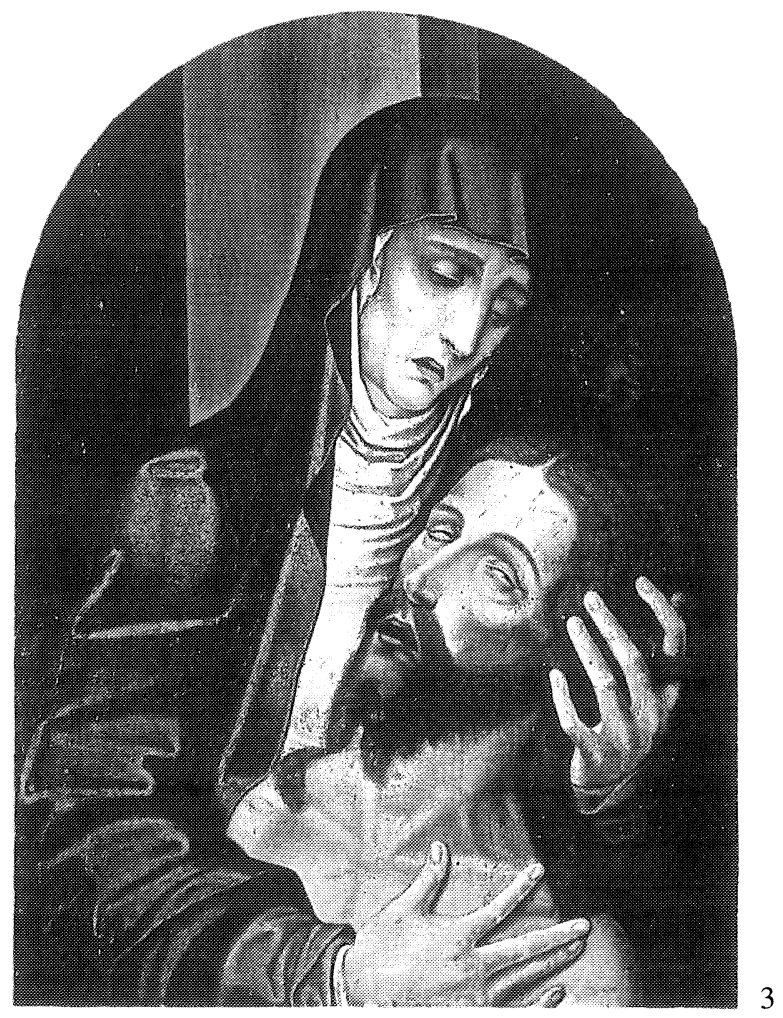

Fig. 1. Luis de Morales, taller: Piedad, tabla sobre madera, colección privada, Praga.

Fig. 2. Luis de Morales, taller: Piedad, tabla sobre madera, detalle, colección privada, Praga.

Fig. 3. Luis de Morales, copia: Piedad, tabla sobre madera, Sigüenza, Museo.

AEA, LXXVIII, 2005, 310, pp. 123 a 131 
La segunda se describe, aunque sin dar a conocer el nombre de Morales, en la primera guía de Praga escrita por el sacerdote Juan Florián Hammerschmid, Doctor en Teología y cura de la iglesia de Týn, aparecida el año de 1723, en la que hace un recuento de las iglesias de Praga y las obras de arte que contienen. Entre ellas, la de la orden de los servitas, donde se guardaban a la sazón dos altares erigidos en honor de La Virgen Dolorosa, existiendo allí mismo, además, una hermandad del mismo nombre ${ }^{29}$. Dado que el monasterio fue liquidado durante las reformas antieclesiásticas del Emperador José $\mathrm{II}^{30}$, los altares pasaron a otros sitios, y el que nos interesa, a la pequeña ciudad de Nejdek, donde, al parecer, ya existía con anterioridad otra versión de la misma Virgen Dolorosa. Aunque se trate de pobres copias, cuya importancia es más histórica que artística, las versiones conservadas interesan sobre todo desde el punto de vista iconográfico porque ilustran la temprana difusión de los modelos de Morales en Bohemia. Hay que reconocer de antemano que las leyendas y las tradiciones se compenetran tanto entre sí que difícilmente podemos determinar su origen, cronología y originalidad. Sin embargo, esto no nos impedirá tratar de sacar los datos principales.

A propósito de la Virgen de Préstice, existe un opúsculo ${ }^{31}$ acerca de la iglesia, así como del cuadro local, copia del cuadro de la iglesia de San Miguel en la Ciudad Vieja de Praga. Este cuadro, colocado por encima del tabernáculo del retablo mayor de dicha iglesia de Přeštice, fue declarado milagroso por el consistorio arzobispal de Praga el día 27 de abril de $1711^{32}$. Otro cuadro de la Virgen de Přeštice está colgado en la capilla de Santa Bárbara de dicha iglesia; esta versión tiene corona, corazón y nimbo de rayos, siendo enmarcada en un marco de chapa de cobre repujado y plateado, realizado en Augsburgo el año de $1712^{33}$.

Su historia es la siguiente ${ }^{34}$ : Para acompañar la lista de los hermanos difuntos, los monjes servitas de San Miguel de Praga, ordenaron realizar una pintura sobre papel de la Virgen de Dolores para consolarse de la muerte de sus hermanos. Una copia de dicho cuadro, asimismo sobre papel, la poseía un ciudadano de Přeštice, llamado Jakub Hofmistr, cuya piadosa mujer la veneraba devotamente. El cuadro, aunque sin valor artístico, le fue muy grato y precioso, de modo que decidió invertir sus pocos bienes en una pintura más decente. Cuando el año de 1686 le recayó la herencia de la casa paterna, encargó una pintura al óleo y sobre lienzo a un pintor de fama, en aquella época y en la región, de la localidad de Dobřany, de nom-

bién una tabla de Cristo con la cruz a cuestas, que sería más bien obra flamenca, aunque importada, sin duda, de España, y que terminó en el monasterio capuchino del Loreto, desapareciendo en el momento de la liquidación del monasterio por los comunistas. Se conservó sólo una foto en el archivo de la Galería Nacional.

${ }^{29}$ Hammerschmid, op. cit. en la nota , Ibíd. cap. VII. Est in hac S. Michalis Ecclesia archi-confraternitas SS. Matris Dolorosae.

${ }^{30}$ Klíma, Stanislav, Země Husova. Historický průvodce po Praze a po Čechách. Praga 1915, p. 46, afirma que los servitas eran irlandeses quienes no sabían el checo, por lo cual después de un tiempo renunciaron al derecho de la parroquia. El monasterio fue liquidado el día 23 de junio de 1786. A su vez, Bartůněk, Václav, «Struné dějiny zrušeného kostela sv. Michala v Praze I» (Breve historia de la iglesia se San Miguel en Praga), Rodokmen (separata), 1946, p. 7, dice, al contrario, que se trataba de monjes italianos y luego locales. Según este estudio, la iglesia y la parroquia fue regalada el día 28V-1627 por el Emperador Fernando II a los servitas, devolviéndoles igualmente su antiguo monasterio Na Trávníčku, a la sazón en ruinas. Los servitas fueron los primeros en construir el monasterio de la Montaña Blanca, en el lugar de la victoria de los imperiales católicos sobre los protestantes, pero al final renunciaron a la empresa. A propósito de la Hermandad, Bartůněk dice (p. 30) que disponía de un escapulario negro; tenía su altar especial, y disfrutaba de varios fueros espirituales.

${ }^{31}$ Kuempel-Staňkovský, Bohuslav, Pamtní spis chrámu Nanebevzetí Panny Marie v Přešticích (Memoria de la iglesia de la Asunción de la Virgen, en Přeštice). Staňkov 1929 (?) quien hace referencia al folleto de Heindl, V., Krátké dějiny a popis děkanského kostela Nanebevzetí Panny Marie v Přešticích (Breve historia y descripción de la iglesia de la Asunción de la Virgen María en Přeštice), así como Ríšák, E. Vl., Dějiny msta Přeštic a jeho okolí. (Breve historia de la ciudad de Př̀štice), II. ed., Př eštice 1928.

${ }^{32}$ Kuempel-Staňkovský, op. cit., pp. 13-144.

${ }^{33}$ Kuempel-Staňkovský, op. cit., p. 17.

${ }^{34}$ Kuempel-Staňkovský, op. cit., p. 21 ss. El cuadro se reproduce asimismo en la obra del mismo autor, Staroeské madony v obrazech (Las viejas Vírgenes checas), sin lugar ni fecha (después de 1940?).

$A E A$, LXXVIII, 2005, 310, pp. 123 a 131 
bre Matj Pazourek. La devota mujer lo colgó en la cámara de su casita modesta y lo tenía en veneración especial, haciéndole una devoción especial cada sábado junto con su marido y sus familiares.

Un día, los esposos piadosos hospedaron en su casa a una viajera. Esta se sumó a la veneración y, ya sola, se quedó velándolo hasta bien entrada la noche, viendo, de repente, un intenso sudor en el cuadro. Despertó a sus huéspedes y les mostró lo ocurrido, pero estos no quisieron que hablase a persona alguna para no perder el cuadro.

Sin embargo de alguna forma trascendió y poco a poco, en los años de la guerra de Sucesión española, la propietaria seguía encontrando en el cuadro gotas de sudor, y en 1710 ya los notaba en una cantidad suficiente. Según la versión que da a conocer Ivo Kořán ${ }^{35}$, observaba ella que del ojo derecho de la Virgen cayeron doce lágrimas en la mejilla derecha del Salvador. El consistorio arzobispal mandó una comisión tras cuyo peritaje el cuadro fue trasladado a la iglesia. En ese lugar sagrado se mostró que las caras del cuadro cambiaban de color y Cristo, para colmo, cierra y abre los ojos y mira hacia el cielo. En 1711, otra comisión había afirmado que el cuadro era milagroso y, el año 1714, fue publicado un librito bajo el título de Atlas Mariano ${ }^{36}$.

Mientras tanto el cuadro sobre papel pasó a otras manos, pero después de un tiempo paró en el monasterio cercano, en cuyo refectorio fue colocado junto con la inscripción siguiente en latín: «La Santa imagen, de donde está tomada la santísima copia de la Reina de los Mártires, de la Dolorosísima Virgen María Madre, besando dulcemente al hijo descendido de la cruz, llorando con sus lágrimas tan milagrosas, tan sobrenaturales las desgracias y las penas del mundo, digna hasta hoy tres veces de asombro, el encuentro del Reino y del Imperio, famosa Milagrosa de Přšstice» ${ }^{37}$.

A propósito del beso, no necesitamos buscarlo en Bizancio como lo sugiere Kořán, sino en la propia Europa Occidental y en España. Basta recordar con Ana Domínguez Rodríguez, que «las disquisiciones de San Bernardo sobre el verso «Bésame con el ósculo de tu boca» (Cant. cant. II) se referían de un modo muy ortodoxo a la Trinidad, pero en la Cantiga 30 (sexta viñeta) (entiéndase de Alfonso el Sabio) se expresan de un modo casi herético al mostrar a Cristo y a la Virgen fundidos en un apretado abrazo y besos, con las caras muy juntas. Esta miniatura anticipa el abrazo entre Cristo y María del Pasionario de la Abadesa Cunegunda (Biblioteca Universitaria de Praga, s. XIV, A 17, f. 16), hija del Rey Otakar II de Bohemia, primo de Alfonso $\mathrm{X}$ el Sabio.» ${ }^{38}$.

La fama del cuadro iba en aumento hasta tal punto que se creó necesario asegurar su difusión por medio de grabados, de los cuales se conservaron dos ejemplares: el primero representa al cuadro sostenido por dos ángeles sobre el árbol de Jesé (éste está durmiendo tendido en el suelo), con un paisaje al fondo que será indudablemente el de la iglesia de Přeštice. Abajo, en la cartela, un letrero reza: «Egredietq Virga de radice Jesse/(et) Flos de radice ejus ascendet. Isaj(as)». Debajo del grabado, otro letrero que confirma que se trata de la Virgen de Přeštice: «Effigies B.V. Mariae Przesticensis apud PP. Benedictinos».

${ }^{35}$ Kořán, Ivo, «Tř́i pra•ské barokní oltáře na Karlovarsku» (Tres retablos en la región de Karlovy Vary), Umění XXXIX, 1991, núm. 6, p. 504.

${ }^{36}$ Sartorius, A., Marianischer Atlas... aus dem grossen Lateinischen Wercke R. P. Guillelmi Gumpenbeg S. I. ... ins Teutsche uebersetzt..., Prag 1717, p. 552 ss. En el Archivo del Arzobispado, depositado en el Archivo Central de Estado, en Praga se guardan dos folios de testimonios acerca de los cambios milagrosos del cuadro. Su culto se extendía cada vez más con réplicas pictóricas, estando una de ellas en el retablo mayor de la iglesia de Stř́bro, así como por esculturas. Kořán, op. cit., ibid.

${ }^{37}$ Kuempel-Staňkovský, op. cit., nota 29 , p. 22

${ }^{38}$ Domínguez Rodríguez, Ana, «Astrología y Arte en el Lapidario de Alfonso el Sabio», Reales Sitios, 1984, núm. 83, p. 12.

$A E A$, LXXVIII, 2005, 310, pp. 123 a 131 
La segunda versión, más popular, representa sólo al cuadro, la segunda copia, por el decorado que le acompaña. También aquí encontramos un letrero que lo identifica: «Vera Effigies B. V. M. Dolorosae in Regia Civitate Misensi/ Sanguinem cum dilecto Filio suo die 20./junij Anno 1737 usq. in presentem horam sudantis» ${ }^{39}$.

Para seguir la pista, hay que regresar a la iglesia del monasterio de los servitas de San Miguel de Praga, en la cercanías de la Plaza de la Ciudad Vieja. El retablo, llamado Virginis Dolorosissimae, fue completado el año de 1751, el crucifijo y el busto del Dios Padre completado en una reconstrucción de $1990^{40}$. Sin embargo, fue fundado por el alcalde de la Ciudad Vieja de Praga, Mikuláš Turek de Rosenthal, ennoblecido por la defensa de Praga contra los suecos protestantes, con el título de Sturmfeld. El año 1705 este retablo fue exornatum, policromado, con la mayor probabilidad. De este retablo habrá encargado, el año 1686, la señora Al•bta (Isabel) Hofmistrová, directamente, o a través de la mencionada copia en el papel, al mencionado pintor Matyáš Pazourek.

Incluso según una copia muy floja podemos reconocer muy fácilmente su modelo: una Piedad de Luis de Morales, del tipo guardado en el Palacio Obispal de Madrid ${ }^{41}$. Dicho tema, en la versión de Morales, aparece como una premonición de las visiones bizantinistas de El Greco. Para concluir, la causa de su presencia en Praga en aquella época será el hecho de que Morales ha sido uno de los pocos pintores cuya fama recorrió toda Europa, o alguna devoción individual de los españoles que pululaban por Praga ${ }^{42}$.

Por coincidencia, se recuerdan tres Dolorosas en los retablos de dicha iglesia, la Piedad milagrosa de madera en el retablo mayor, otra en el retablo de las Cinco Llagas de Cristo, del año 1700 y finalmente, la citada Dolorosísima en el retablo del alcalde Turek. Los informes conservados son del primer tercio del siglo xIx, cuando fue trasladado dicho altar, que a finales del siglo XVII fue pintado para la iglesia ${ }^{43}$, por un pintor de quien se conoce sólo el nombre, esta vez un alemán, Anton Hanot de Mons, activo en Hennegau. A la muy venerada Virgen Dolorosa agregó luego dos figuras el mejor de los pintores barrocos checos Petr Brandl, y aún más tarde, las almas en el purgatorio otro pintor, Jan Quirin Jahn ${ }^{44}$

De la confrontación de los datos puede derivarse que el cuadro de Hannot (Schramm) estuvo en el retablo de las Cinco Llagas, mientras que la Dolorosísima de Turek habrá surgido antes de 1661. Aunque no puede excluirse que Hannot hubiera imitado directamente a una obra de Morales ya antes de 1686 cuando surge la copia de Přeštice, Kořán prefiere creer que el cuadro original de Morales estaba antes en el altar de Turek. Además, sugiere que habría procedido de las colecciones de Rodolfo II, siendo más tarde robado por los suecos y, al igual que un famoso cuadro del Salvador en la ciudad de Chrudim, habría pasado, debido a un episodio bélico, a la propiedad del valiente combatiente contra los suecos Turek quien, a su vez, lo habría

\footnotetext{
${ }^{39}$ Royt, Jan, Obraz a kult v Čechách 17. a 18. století. Praha 1999, p. 67, fg. 5, se trata de una obra de Anton Birckhart, según dibujo de J. Hiebl: Cuadro de la Virgen de Přeštice, grabado al cobre, hacia la mitad del s. XVIII. Los grabados están guardados en el Museo de las Letras Checas (Památník národního písemnictví), y la hoy renovada Real Canonjía de los Premonstratenses de Strahov.

${ }^{40}$ Umélecké památky Čech, II, Academia Praha 1978, Ed. E. Poche, p. 458; Kořán, op. cit., p. 504.

${ }^{41}$ Publicado por Gaya Nuño, op. cit., repr. 38, o una réplica suya desconocida en la cual la Madre mantiene la cabeza de Cristo con las dos manos.

${ }^{42}$ Kořán, op. cit., alude a una obra posiblemente no publicada que se encuentra en la ciudad de Zagorsk, de Rusia.

43 «mit vieler Geschicklichkeit», Kořán, ibid., p. 505.

${ }^{44}$ Según el historiador más antiguo checo, Dlabacz, Jan Bohumír, Allgemeines historischer Kunster-lexikon fuer Boehmen, II. Praga 1815, p. 436. Sobre las relaciones del cuadro de la iglesia de los servitas véase Aurenhammer, H., Die Mariengnadenbilder Wiens und Niederoesterreichs in de Barockzeit, Wien 1956. Véase también Kořán, op. cit., p. 509, nota 7. Además, por él no citado Julius Max Schottky, Prag, wie es war und wie es ist, I, Praga 1831, p. 297 quien da a conocer que originalmente, la iglesia de los servitas pertenecía a los templarios. En Praga se le conocía a Anton Hannob («zu Mons im Hennegau geboren») bajo el nombre de Schramm (Schramme), es decir Cicatriz. P. Brandl (1668-1735), J. Q. Jahn (1739-1802).
}

$A E A$, LXXVIII, 2005, 310, pp. 123 a 131 
colocado en el retablo. Esto, sin embargo, son meras especulaciones, como el propio Kořán reconoce ${ }^{45}$.

Los cambios de la pintura, calificados de «milagrosos», parecen ser muy «orgánicos» ${ }^{46}$ dado el origen bizantino-español del tema y se notan en otras copias de la copia de Přeštice. La más cercana, enmarcada en un rico marco de plata, muestra a la Virgen con párpados semicerrados, mientras que los ojos de Cristo están vueltos hacia el cielo. En la segunda, a la Virgen le salen lágrimas, y finalmente, en la tercera, decorada con una corona y nimbo de oro, llora con ojos abiertos. Según Kořán, podría haber sospecha de «pia fraus» del cambio sucesivo del motivo de los cuadros ${ }^{47}$, pero en realidad dichas variantes surgieron como ecos de los «milagros» recordados.

Además, hay que aceptar las diferentes versiones como testimonio de la difusión de la mística española en el ambiente popular del Reino de Bohemia, y como una representación del cambio en la recepción de la expresión de la pintura en el transcurso de una oración intensa. Para colmo, existía aún una versión en la ciudad de Přeštice ${ }^{48}$, y allí mismo surgió un relieve del mismo tema, decorado con nimbo (Cristo) y la corona (la Virgen), y sostenido, como corresponde a su fecha más tardía, por un grupo de angelitos (cabezas) sobre nubes ${ }^{49}$.

Así vemos que la Dolorosa de Morales, cuyo original o versión que había desaparecido, concuerda con la que está en una colección privada de Praga sin poder ser identificada con el modelo del cuadro que comentamos. Pero ésta es otra prueba de la difusión de la obra de Morales en el mundo.

\footnotetext{
${ }^{45}$ Kořán, op. cit., ibid. A propósito de las colecciones rodolfinas, véase como testimonio indirecto, la presencia de un tema iconográfico muy estrechamente ligado con Morales presentado en la exposición Rudolf II. a Praha. Císařský dvưr a rezidenční mèsto jako kulturní a duchovní centrum Střední Evropy. Katalog vystavených exponátů. Praha 1997 (cat. ed. E. Fučíková), núm. II/131, Philippe van den Bossche, obra de un escultor en cera anónimo de la corte de Rodolfo II. Altar portátil con el motivo de La virgen llora por Cristo (caja de ébano, cera, tela y seda bordada, decoraciones de latón, placas de lapislázuli acabado con pintura al óleo, marfil), realizado entre 1604-15 y propiedad hoy de The Trusters of the British Museum de Londres, con un letrero que dice: OMNIA DISPLICEANT QVAM VIS MORTALIA. NVMQVAM / MORTVVS HIC POTERIT DISPLICVIS SE MIHI.

${ }^{46}$ Palabra de Kořán, op. cit., ibid.

${ }^{47}$ Kořán, ibid, p. 505, recuerda que hay un Cristo de miembros movibles en la ciudad de Klatovy que los jesuitas utilizaban al visitar a los moribundos, moviendo la cabeza o los miembros de Cristo según necesidad. Quizás se recoge aquí la tradición española que describe el viajero checo Václav Šašek de Bířkov el año 1465. En un monasterio cerca de Burgos, los checos vieron una cruz, encontrada a la orilla del mar; en esa cruz había una imagen de Cristo con cabellos y barba naturales. Según Šašek, «un sacerdote al subir al altar, tocaba todos sus miembros y los movía, las piernas, las manos y todas las articulaciones». Véase Václav Šašek de Bířkova, Deník o jízdě a aputování pana Lva z Ro•mitálu a z Blatné z ech $a \bullet$ na konec světa. (Diario del viaje y peregrinación del señor Leo de Rosmital y de Blatná de Bohemia hasta el fin del mundo). Praga 1974, p. 78

${ }^{48}$ Umělecké památky Čech, op. cit., III, p. 175-177 alude a dos cuadros del mismo tema, pero el segundo resulta una copia de la primera copia que comentamos, sin calidad alguna. Advierte que nuestro cuadro en cuestión está en un marco repujado y plateado, realizado en Augsburgo en 1712, mientras que el marco de la segunda copia es rococó del año 1773. Recuerdo haber visto una versión, aún de aceptable calidad, en una tienda de anticuario de Praga ( el día 25-I-1972, de tamaño de $35 \times 25$, pero de muy baja calidad), y luego varias versiones de pésima calidad, incluyendo una miniatura en una colección privada, de tamaño que corresponde al grabado $(18 \times 14$, con las líneas de contorno doradas, como corresponde al segundo grabado arriba comentado), todas derivadas del mismo prototipo. Este se relaciona, pero no se identifica, con las piedades de Badajoz y de la Academia de San Fernando de Madrid.

${ }^{49}$ Kuempel, op. cit., en el frontispicio.
} 